\title{
Uma Proposta de Uso da Metodologia WebQuest para o Ensino e Aprendizagem de Literatura
}

\author{
Nataniel Mendes da Silva - mestrando do Programa de Pós-Graduação Cultura e Sociedade da \\ Universidade Federal do Maranhão - nataniel@ifma.br \\ João Batista Bottentuit Junior - Professor Permanente do Programa de Pós-Graduação Cultura e \\ Sociedade da Universidade Federal do Maranhão jbb@terra.com.br
}

\section{RESUMO}

As constantes transformações sociais engendram, na mesma proporção, transformações educacionais. A relativa popularização de computadores e dispositivos móveis conectados à internet trouxe significativos avanços para a educação. Professores e alunos estão constantemente descobrindo novas formas de ensinar e aprender. Uma dessas formas é metodologia de pesquisa orientada na Web, a WebQuest. O presente artigo apresenta um caso prático, a WebQuest Aventura na Web com Clarice Lispector, desenvolvida com alunos da terceira do ensino médio de uma escola pública em São Luís. A pesquisa mostra que a utilização da metodologia WebQuest, associada às ferramentas da Web 2.0, estimula a autoria, criatividade e o trabalho colaborativo, facilitando e redimensionando, assim, o processo ensino-aprendizagem.

Palavras - chave: WebQuest, Tecnologias da Informação e Comunicação, Web 2.0.

\section{A Proposal for Use of Methodology WebQuest for Teaching And Learning Literature}

\begin{abstract}
The constant social changes engendered by the same proportion, educational transformations. The relative popularity of computers and mobile devices connected to the internet has brought significant advances in education. Teachers and students are constantly discovering new ways of teaching and learning. One of those ways is research methodology oriented Web, the WebQuest. This paper presents a practical case, the WebQuest Adventure Web with Clarice Lispector, developed with students of the third high school in a public school in St. Louis Research shows that the use of WebQuest methodology, associated with Web 2.0 tools, encourages authorship, creativity and collaborative work, facilitating and thus resizing the teaching-learning process.
\end{abstract}

Key - words: WebQuest, Information Technologies and Communications, Web 2.0

\section{INTRODUÇÃO}

O processo ensino-aprendizagem, como tudo na sociedade de informação, vem passando por intensas transformações. A tecnologia traz impactos em todos os setores da sociedade. O dinamismo das tecnologias traz à tona a complexidade de suas implicações sociais, culturais e, portanto, educacionais. A escola, sem sombra de dúvida, não está isenta desse processo. Ao contrário, ela é, ou pelo menos deveria ser, o 
ponto de partida para compreensão dessas mudanças e inserção do indivíduo neste novo mundo. Para Buzato (2006), pensar nas tecnologias de informação e comunicação - TIC - como oportunidades de melhorar o mundo é, obrigatoriamente, pensar em educação.

Claro que a tecnologia é inócua se não for associada a metodologias apropriadas às demandas da Sociedade de Informação, que, segundo Coutinho (2006), detém novas formas de comunicação e acesso à informação suportadas pela Internet, assentes na interação, partilha e colaboração e "exigem uma abordagem holística ao processo educacional que passa pela integração da tecnologia no currículo com vista a uma expansão do mesmo e a uma participação mais ativa dos alunos no processo de ensino/aprendizagem”.

Pensando nisso, selecionamos uma metodologia de pesquisa orientada, que usa recursos da internet para realização de tarefas propostas por professores, a WebQuest, para avaliar sua eficiência no ensino de literatura. O presente artigo apresenta as possibilidades de uso das ferramentas da Web 2.0, analisando um exemplo prático, a WebQuest - WQ Aventura na Web com Clarice Lispector ${ }^{1}$. No primeiro momento faremos uma explanação sobre as tecnologias computacionais e a Web 2.0. Em seguida, apresentaremos o conceito, vantagens e potencialidades e estrutura da metodologia WebQuest. A partir daí, apresentaremos a WQ proposta, analisando de que forma as ferramentas da Web 2.0, utilizadas na resolução das tarefas solicitadas, podem corroborar para uma aprendizagem mais significativa.

\section{TECNOLOGIAS DE INFORMAÇÃO E COMUNICAÇÃO E WEB 2.0}

Antes de se falar sobre tecnologia aplicada à educação, é conveniente que se fale sobre a relação obrigatória que a sociedade, sobretudo a urbana, tem cotidianamente com os recursos tecnológicos. Desde a invenção da escrita até o microprocessador de dados, o aparato tecnológico produzido pela humanidade vem modificado a cultura, a economia, a linguagem, a política, a educação etc. O telégrafo, o telefone, o rádio, a televisão, o computador e os dispositivos móveis como smartphone, tablet, ipad, conectados à internet revolucionaram a forma como as pessoas trabalham, compram, comunicam-se, entretêm-se, estudam, pesquisam, aprendem. Enfim, a tecnologia muda a forma de como as pessoas vivem, a cultura e todas as suas nuances são alteradas. Conforme Martín-Barbero (2006),

o lugar da cultura na sociedade muda quando a mediação tecnológica da comunicação deixa de ser meramente instrumental para espessar-se, condensar-se e converter-se em estrutural: a tecnologia remete, hoje, não a alguns aparelhos, mas, sim, a novos modos de percepção e de linguagem, a novas sensibilidades e escritas (MARTÍN-BARBERO, 2006, p. 54, grifo nosso)

A tecnologia atua não somente como suporte instrumental, mas como elemento estrutural das relações sociais. Distâncias espaciais e temporais estão cada vez mais curtas ou quase inexistentes em alguns casos. Mensageiros instantâneos, fóruns de informação, áudio, videoconferências e troca incessante de informações são alguns dos ingredientes compartilhados por milhões de usuários no ciberespaço ${ }^{2}$.

A escola, como parte integrante dessa sociedade em movimento, não pode ficar alheia às transformações. Deve, sim, reconsiderar as formas tradicionais e instrucionistas de ensino centradas na figura do professor e proporcionar aos educandos experiências autorais e colaborativas de aprendizado. As TIC, em especial através do uso das ferramentas da Web 2.0, devem ser incorporadas ao fazer docente, não porque vão acabar com os problemas educacionais brasileiros, mas porque valorizam as novas 
formas de se construir conhecimento, fazem uma interlocução com o cotidiano da sociedade e, portanto, dos alunos, além de colocá-los como centro do processo ensinoaprendizagem. Web 2.0 é um termo cunhado por Tim O‘Reilly (2005). Para ele,

is the business revolution in the computer industry caused by the move to the Internet as a platform, and an attempt to understand the rules for success on that new platform. Chief among those rules is this: Build applications that harness network effects to get better the more people use them. This is what I've elsewhere called "harnessing collective intelligence. (O'REILLY, 2005) $)^{3}$

Esse novo paradigma da rede mundial de computadores privilegia contatos em rede, interação, a autoria e a colaboração. O usuário da Internet deixa de ser um mero espectador e consumidor de serviços para tornar-se, ao lado de tantos outros usuários, produtor e colaborador nessa troca e compartilhamento incessantes de informações, formando uma espécie de inteligência coletiva.

Os principais pontos das mudanças paradigmáticas da Web 1.0 para a chamada Web 2.0 são sintetizados por Bottentuit Junior e Coutinho (2008) na tabela 1:

Tabela 1: Diferenças entre a Web 1.0 e a Web 2.0

\begin{tabular}{|l|lr|}
\hline O utilizador é consumidor da Informação; & $\begin{array}{l}\text { O utilizador é consumidor e produtor da } \\
\text { informação; }\end{array}$ \\
\hline $\begin{array}{l}\text { Existem dificuldades inerentes à programação } \\
\text { e aquisição de softwares específicos para } \\
\text { criação e gestão de páginas na Internet; }\end{array}$ & $\begin{array}{l}\text { Há facilidades de criação e edição de páginas } \\
\text { de forma online; }\end{array}$ \\
\hline $\begin{array}{l}\text { Para ter um espaço grande na rede, na maioria } \\
\text { dos servidores, é necessário pagar; }\end{array}$ & $\begin{array}{l}\text { O utilizador tem vários servidores para } \\
\text { disponibilizar páginas de forma gratuita; }\end{array}$ \\
\hline $\begin{array}{l}\text { Menor número de ferramentas e e } \\
\text { possibilidades; }\end{array}$ & $\begin{array}{l}\text { Maior número de ferramentas e e } \\
\text { possibilidades; }\end{array}$ \\
\hline Pouca interatividade e poucas redes sociais. & $\begin{array}{l}\text { Muita interatividade e quase todos os } \\
\text { aplicativos estimulam a criação de laços } \\
\text { sociais com os demais utilizadores. }\end{array}$ \\
\hline
\end{tabular}

As novas possibilidades de criação e edição de páginas online, a disseminação de aplicativos que estimulam a interação entre usuários são um convite aos alunos à participação na rede mundial de computadores, sobretudo para os nativos digitais ${ }^{4}$.

Essa geração já não enxerga o professor como detentor da informação, como aquele sujeito transmissor do conhecimento. Em tempos de Internet e disponibilidade de informações, o (a) professor (a) deve ser um (a) animador (a), no sentido mais pedagógico da palavra. Aquele (a) que estimula, incentiva, acompanha e, principalmente, orienta seus educandos nos caminhos do conhecimento. Como uma dessas possibilidades, apresentamos a WebQuest, uma metodologia que existe desde 1995 e vem sendo objeto de estudo de pesquisadores ao redor do mundo.

\section{WEBQUEST: conceito, vantagens e potencialidades}

Em 1995, o professor de Tecnologia Educacional da San Diego University, Bernard Dodge, e seu aluno de graduação, Thomas March, a partir de um imprevisto, criaram a metodologia de pesquisa orientada na Web, a WebQuest (WQ). Dodge precisou demonstrar para um grupo de professores em formação o funcionamento da simulação educacional, a partir do uso de um software chamado Arquetype. O que ele 
não contava é que naquele momento não dispunha de uma cópia do programa, tampouco de equipamentos que pudessem viabilizar a demonstração. O que fazer diante de uma audiência à espera de uma aula que, naquele momento, não poderia ser ministrada da forma como fora planejada? Esse tipo de situação pode acabar com uma aula; ou, então, fomentar a criatividade e a descoberta de novas estratégias de ensino por parte dos educadores.

Foi exatamente o que o professor e pesquisador Bernard Dodge fez, usou sua criatividade e pediu para que os alunos, de forma colaborativa, buscassem informações na Web, previamente selecionadas pelo docente, sobre o programa em questão. Então preparou uma tarefa em que os alunos, a partir das informações colhidas e da avaliação feita por eles, deveriam redigir um documento, sugerindo ou não o uso do software Arquetype. O resultado foi surpreendente, Dogde percebeu que os alunos se sentiram desafiados e executaram a tarefa com muito afinco. Houve um comprometimento dos alunos em pesquisar de forma profunda o tema a partir dos recursos oferecidos e da interação com seus pares.

A partir dessa bem-sucedida experiência, Bernard Dodge passou a aperfeiçoar e, o mais interessante, compartilhar com outros educadores o incipiente e promissor método de ensinar e aprender, a WebQuest. Ele publicou um artigo intitulado WebQuests: A Technique for Internet, em que define a WQ como uma investigação orientada na qual algumas ou todas as informações com as quais os aprendizes interagem são originadas de recursos da Internet.

Para que o objetivo educacional de uma WQ seja atingido, Dodge ${ }^{5}$ (1995) estabeleceu atributos que devem ser apresentados e dispostos na seguinte ordem:

1) uma introdução que prepare o "palco" e forneça algumas informações de fundo;

2) uma tarefa factível e interessante;

3) um conjunto de fontes de informações necessárias à execução da tarefa. Muitos (não necessariamente todos) dos recursos estão embutidos no próprio documento da WQ em forma de 'âncoras' que indicam fontes de informação na Web. As fontes de informação podem ser: especialistas disponíveis via e-mail ou conferências online, base de dados pesquisáveis na rede, livros e/ou documentos, arquivos acessíveis no ambiente de aprendizagem ou trabalho dos participantes;

4) uma descrição do processo que os aprendizes devem utilizar para efetuar a tarefa. O processo deve estar dividido em passos claramente organizados e descritos;

5) alguma orientação sobre como organizar as informações adquiridas. Isto pode aparecer sob a forma de questões orientadoras ou como direções para completar as metas estabelecidas no prazo;

6) uma conclusão que encerre a investigação, demonstre aos alunos o que eles aprenderam e, talvez, os encoraje a levar a experiência para outros campos não explorados dentro da WQ.

Observamos que a metodologia WQ não se trata de um conjunto de exercícios divulgada na Web. Sua elaboração segue etapas criteriosas e desafiadoras para docentes e discentes. Estes enveredam por um caminho cuidadosamente guiado.

Apresentamos agora um caso prático, a WebQuest "Aventura na Web com Clarice Lispector”, desenvolvida com alunos da terceira série do ensino médio de uma escola pública em São Luís. 


\section{EXEMPLO PRÁTICO}

A WebQuest ${ }^{6}$ "Aventura na Web com Clarice Lispector" na página de apresentação, conforme a figura 2, traz uma citação da autora "Renda-se, como eu me rendi. Mergulhe no que você não conhece como eu mergulhei”, acompanhada de sua caricatura. Clarice Lispector é notoriamente conhecida pela forma como conta suas histórias, com ênfase nos aspectos psicológicos das personagens, um verdadeiro “mergulho' à introspecção. Logo na apresentação, o substantivo aventura, os verbos render-se e mergulhar, associados à leveza e ao humor da caricatura, reforçam as ideias de imersão, atividade, convite, tarefa; ou melhor, de desafio.

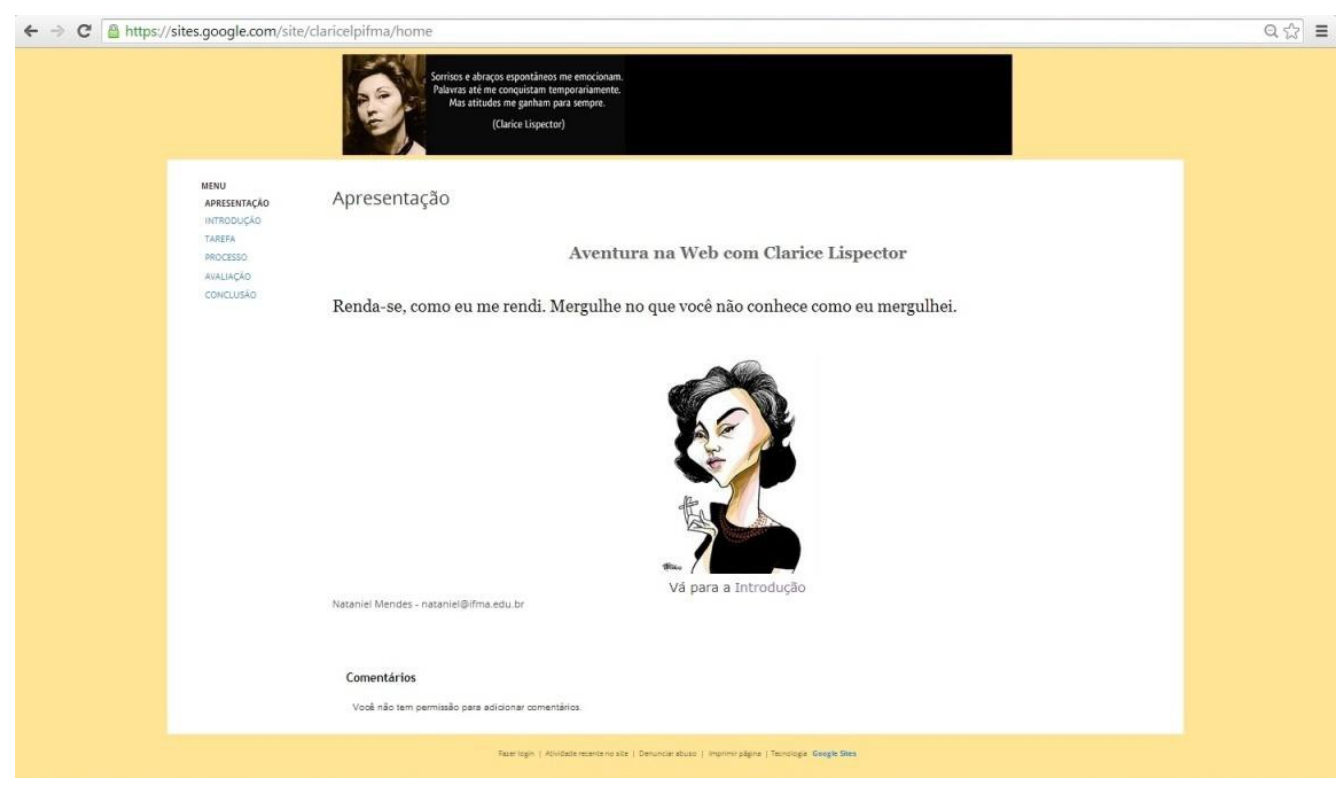

Figura 1: Apresentação

Embora Clarice Lispector tenha falecido em 1977, aqui ela "está viva”. Na metodologia WQ, há possibilidades de se trabalhar com simulações. É possível, por exemplo, que os alunos assumam a função de jornalistas, cientistas, detetives etc. $\mathrm{Na}$ introdução, conforme figura 3, a própria autora "prepara o palco” para a atividade.

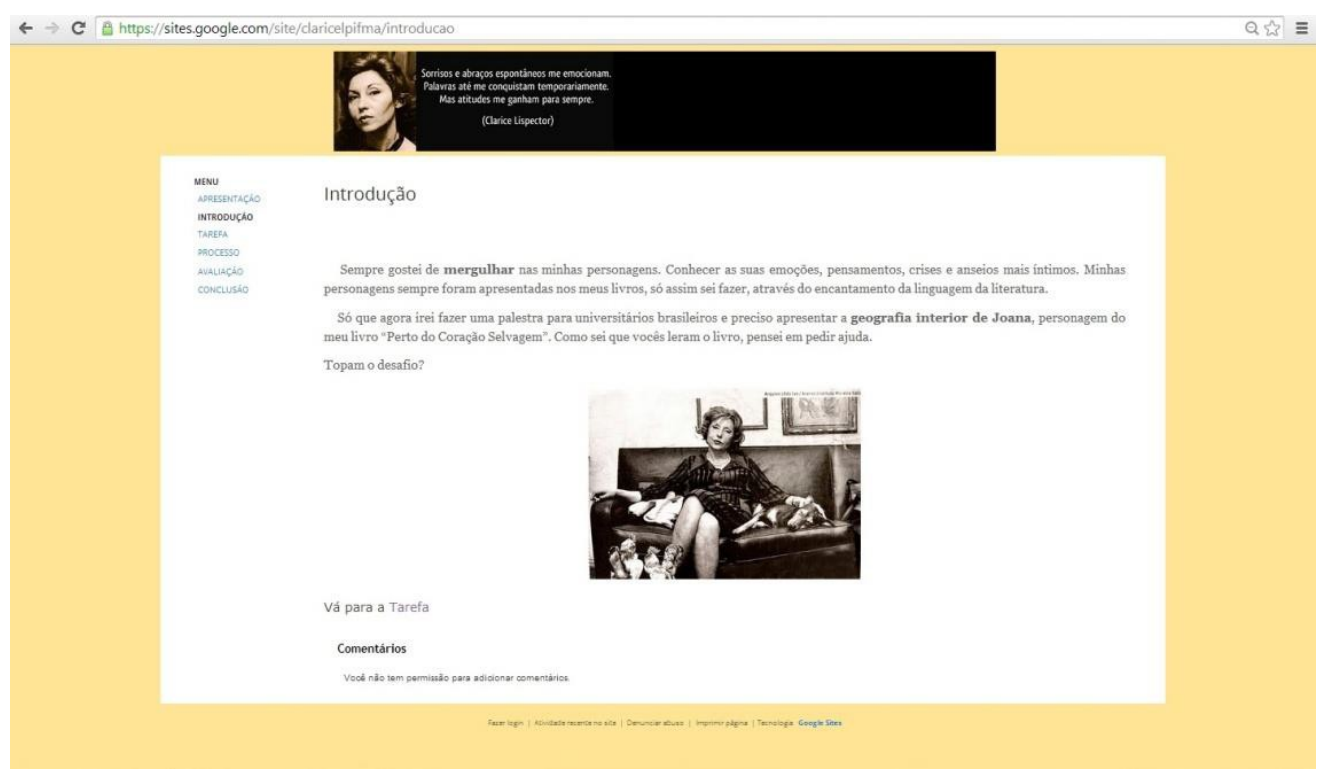

Figura 2: Introdução 
Com o objetivo de despertar os alunos para o assunto - motivação temática - e recuperar os conhecimentos prévios ${ }^{7}$ - motivação cognitiva (Dodge, 2007), necessários à resolução da WQ, a introdução é apresentada através de uma situação hipotética em que autora precisa da ajuda dos alunos para apresentar a um grupo de universitários a "geografia interior" de Joana, protagonista do romance "Perto do Coração Selvagem".

A tarefa, coração da WQ (Barato, sd), é norteada pela hipotética palestra de título "Revelando a geografia interior de Joana". Para a realização das tarefas, achamos oportuno sugerir o uso de ferramentas da Web 2.0, como o podcast, prezi e o blog. Assim, além de despertar o interesse temático, a ideia era também aguçar a curiosidade de jovens de dezessete anos, que, geralmente, se interessam e aprendem com muita facilidade novos recursos tecnológicos.

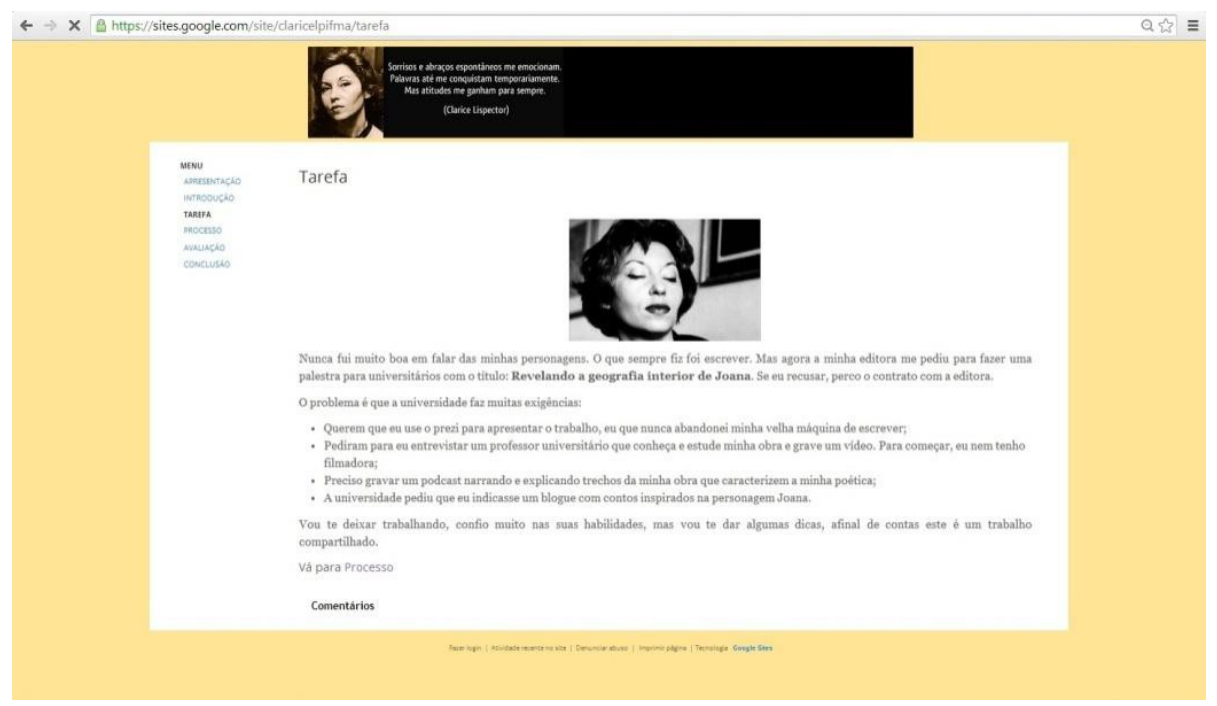

Figura 3: Tarefa

Um dos cuidados, ao se elaborar a tarefa de uma WQ, é com o aspecto real ou cotidiano do desafio. Nos livros didáticos, em geral, são comuns atividades que se distanciam da realidade dos alunos e acabam gerando desmotivação por conta da excessiva abstração, quando da abordagem dos conteúdos. Para March (2000), as WQ devem ser reais, ricas e relevantes.

A propósito, embora o foco da tarefa proposta seja sobre literatura, área do conhecimento que, naturalmente, explora o caráter ficcional do texto, a realidade, riqueza e relevância não são desprezadas. Ao contrário, aqui a leitura, competência fundamental para qualquer aluno, é tomada como um constante devir, um inacabado processo. Esse interminável processo, sem dúvida, faz parte da realidade dos alunos não só no trabalho com a língua propriamente dito, mas no trabalho com leitura de todas as disciplinas. Corroborando com a ideia de que o ato de ler é inesgotável, Leite (1988) afirma que

A leitura, na verdade, é uma arte em processo. Como Goethe, poderíamos todos reaprender a ler a cada novo texto que percorremos. Mas há sobretudo muito a aprender quando percebemos que ler não é apenas decifrar o impresso, não é um mero "savoir-faire”, a que nos treinaram na escola, mas ler é questionar e buscar respostas na página impressa para os nossos questionamentos, buscar a satisfação à nossa curiosidade. (LEITE, 1988, p.91)

Então, explorar as potencialidades do texto literário e ter a oportunidade de compartilhar com os colegas as experimentações ocorridas durante a leitura parece-nos uma atividade pedagógica extremamente enriquecedora para docente e discentes. A 
relevância consiste exatamente na necessidade que os alunos-leitores têm de resinificar suas leituras, principalmente se tratando do texto literário, que é aberto a múltiplas percepções.

O processo foi divido em duas etapas. A primeira, comum a todos os grupos, consiste na apresentação de informações sobre a autora e sua produção literária, através de textos escritos e vídeos com depoimentos de especialistas. Na segunda etapa cada grupo tem acesso às especificidades das tarefas, bem como as ferramentas que deverão ser utilizadas para a apresentação dos resultados. Optamos por integrar a esta etapa os recursos necessários para a realização das tarefas, por acreditarmos que isso garante mais fluidez à pesquisa.

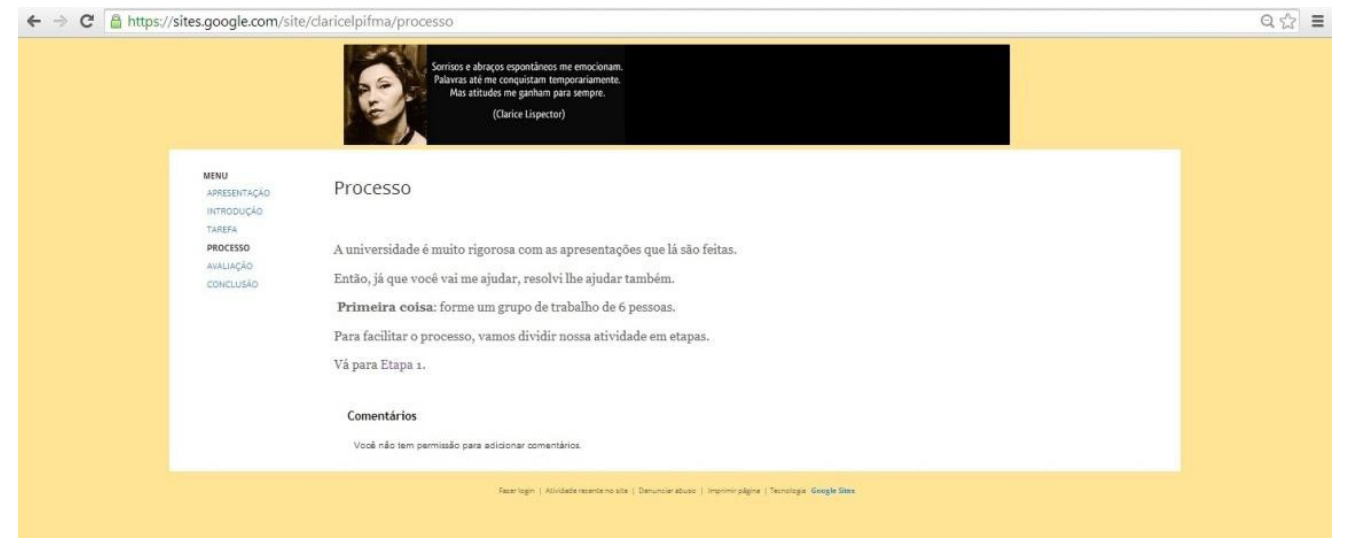

Figura 4: Processo

$\mathrm{Na}$ avaliação, os alunos devem saber exatamente como o produto final das tarefas será avaliado e o que será considerado na avaliação do trabalho da equipe. Nesta etapa, a partir de uma reconsideração do resultado, o grupo pode inclusive, se os membros julgarem conveniente, refazer a tarefa, conforme aponta Abar e Barbosa (2008):

\begin{abstract}
A avaliação, componente primordial da WebQuest, deve apresentar aos alunos, com clareza, como o resultado da tarefa será avaliado e que fatores serão considerados. Os fatores podem ser explicados em valores porcentuais em relação ao trabalho desenvolvido. Desse modo, os alunos saberão também avaliar a qualidade do trabalho e podem, de maneira colaborativa, rever ações e reconstruir, se necessário, o produto final, objeto da tarefa. (ABAR e BARBOSA, 2008, p. 47).
\end{abstract}

No caso da avaliação da WQ "Aventura na Web com Clarice Lispector”, atribuímos peso de $60 \%$ aos aspectos mais relevantes do conteúdo do livro em questão e os outros $40 \%$ distribuímos, conforme figura 5, levando em conta os seguintes aspectos:

$\checkmark$ Clareza, objetividade e rigor da linguagem;

$\checkmark$ Capacidade de pesquisa e organização da informação;

$\checkmark$ Apresentação visual;

$\checkmark$ Empenho e espírito de grupo. 


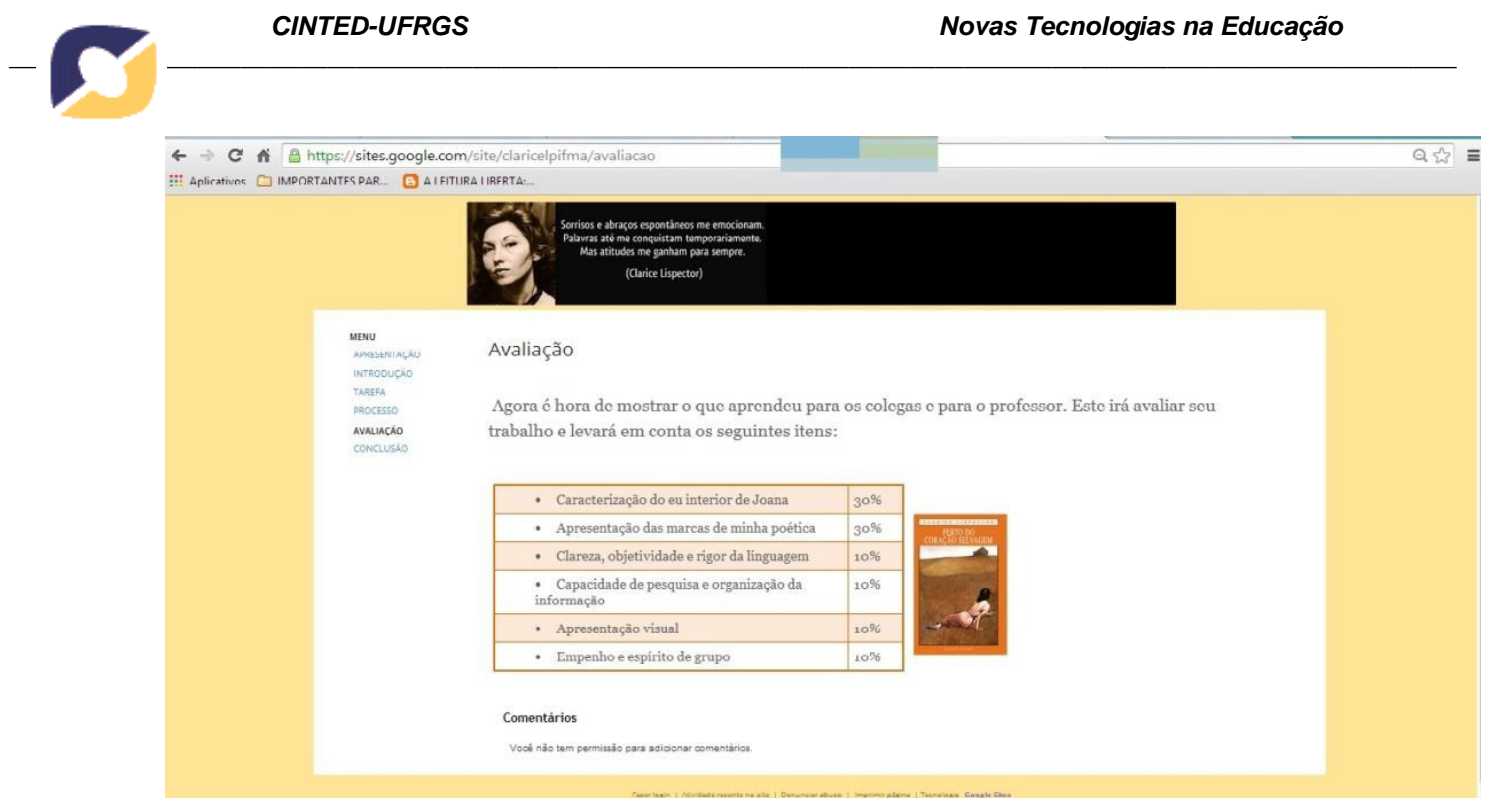

Figura 5: Avaliação

A etapa conclusão é sempre provisória, no sentido de não dar necessariamente um fechamento às questões motivadoras da introdução nem ao desafio proposto na tarefa.

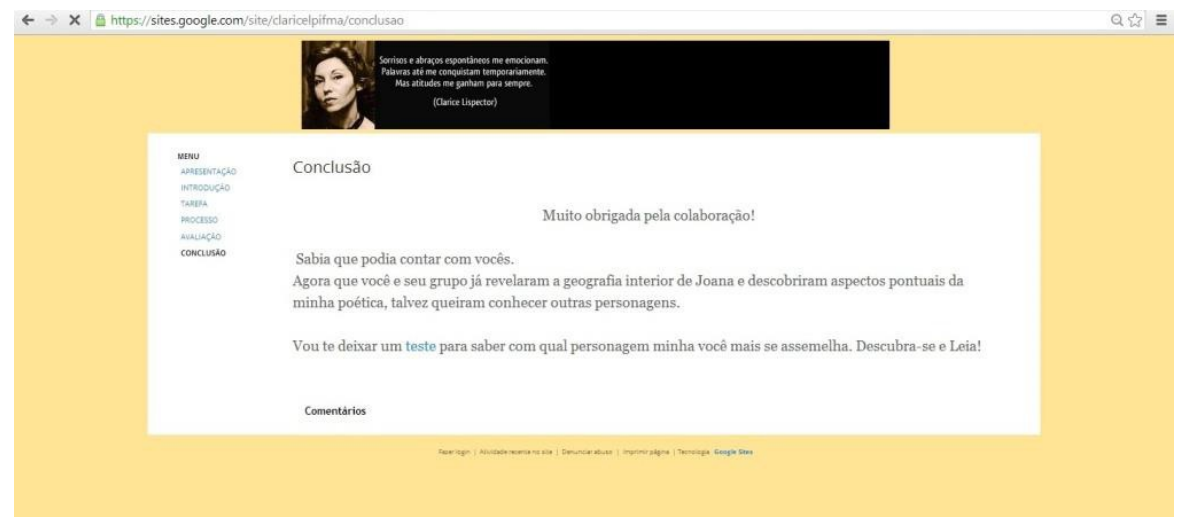

Figura 6: Conclusão

Na conclusão da WQ em análise, a escritora Clarice agradece a ajuda, diz o que foi possível descobrir e indica um pequeno teste de personalidade promovido pela Revista Educar para Crescer, para que os alunos possam descobrir com qual personagem da escritora mais se assemelham. A partir desse teste, os alunos conhecem personagens de outras obras e, provavelmente, muitos se sintam motivados a continuar conhecendo a obra da escritora.

\section{CONSIDERAÇÕES FINAIS}

No que se refere ao caso concreto apresentado, a receptividade dos alunos à proposta apresentada, bem como os materiais produzidos por eles apontam para um cenário bastante alvissareiro, no que diz respeito ao uso de WQ como metodologia de ensino e aprendizagem. O desafio proposto é sempre para todos, o que inclui docente e discentes. A produção da WQ, embora não requeira grande conhecimento de informática, revelou-se desafiadora, no sentido de "garimpar" material relevante sobre a temática e que, ao mesmo tempo, fosse acessível e estimulante para a plateia, neste caso 35 alunos de 17 anos.

Durante a execução das tarefas os alunos se mostraram muito empenhados e comprometidos com o trabalho, o que foi percebido através do monitoramento do grupo criado na rede social Facebook. Através deste canal de informal de comunicação, os alunos distribuíram-se em grupos, postaram seus avanços no desenvolvimento das tarefas e divulgaram matérias veiculadas sobre Clarice Lispector durante o 
desenvolvimento da WQ. Uma das vantagens dessa estratégia foi que o contato entre alunos e professor não ficou restrito à sala de aula. Assim o professor tem a possibilidade de monitorar as atividades, dar sugestões, fomentar o debate e o trabalho colaborativo.

Outro ponto que, embora não seja obrigatório na metodologia WQ, favoreceu bastante o comprometimento com o resultado foi à criação de um blog ${ }^{8} \mathrm{com}$ as produções dos alunos. Esse recurso funcionou como um espaço de reflexão e avaliação dos pensamentos e práticas dos alunos. Uma vez que o resultado ficaria disponível na Web, a preocupação passou a ser maior quando comparada à apresentação somente em sala de aula.

No que diz respeito especificamente ao trabalho com literatura, a resolução das tarefas da WQ pareceu muito mais desafiadora e interessante do que um debate ou uma prova escrita, por exemplo. Os métodos tradicionais costumam privilegiar a memorização em detrimento da manipulação das informações para produção de conhecimento. Ler um livro para “fazer prova” não é nada desafiador, quando comparado a uma atividade jornalística ou mesmo de crítica literária em que alunos são desafiados a perscrutar e percorrer o íntimo de uma personagem e tentar construir um perfil psicológico. Assim é possível compreender uma característica que marcou a produção literária de Clarice Lispector: a viagem pelo mundo da introspecção.

Os resultados apresentados são preliminares e comporão uma análise mais detalhada, quando da redação de uma dissertação de mestrado do Programa de PósGraduação Cultura e Sociedade da Universidade Federal do Maranhão. O presente estudo pretendeu apenas testemunhar um caso prático que comprova a eficiência da metodologia também nos estudos literários.

\footnotetext{
${ }^{1}$ WebQuest produzida por Nataniel Mendes como uma das etapas da pesquisa "A WEBQUEST NA AULA DE LITERATURA: um estudo de caso com alunos do $3^{\circ}$ ano do ensino médio" vinculada à pesquisa de mestrado do Programa de Pós-Graduação Cultura e Sociedade da Universidade Federal do Maranhão - MA sob orientação do Prof. Dr. João Batista Bottentuit Junior docente permanente do programa.

2 “[...] espaço de comunicação aberto pela interconexão mundial dos computadores e das memórias dos Computadores.” (LÉVY, 1999, P. 92).

${ }^{3}$ Web 2.0 é a mudança para uma internet como plataforma, e um entendimento das regras para obter sucesso nesta nova plataforma. Entre outras, a regra mais importante é desenvolver aplicativos que aproveitem os efeitos de rede para se tornarem melhores quanto mais são usados pelas pessoas (o que eu tenho chamado de "aproveitando a inteligência coletiva").

${ }^{4}$ Termo cunhado pelo educador e pesquisador Marc Prensky (2001) para descrever a geração nascida após a popularização de computadores pessoais e da internet. Essa geração consome e produz informações e as divulga através de blogs e redes sociais digitais.

${ }^{5}$ Utilizamos uma tradução realizada pelo Prof. Jarbas Novelino Barato, do artigo: WebQuests: A Technique for Internet - Based Learning, publicado em The Distance Educator, v.1, n 2, 1995. O artigo traduzido encontra-se no site: http://www.dm.ufscar.br/ jpiton/downloads/artigo_webquest_original_1996_ptbr.pdf, acesso em $31 / 03 / 2014$

${ }^{6}$ URL da WebQuest Aventura na Web com Clarice Lispector https://sites.google.com/site/claricelpifma/home

${ }^{7}$ Foi solicitada aos alunos, um mês antes da resolução da WQ, a leitura da obra "Perto do Coração Selvagem.

${ }^{8}$ URL do blog http://aventuraclarice.wix.com/aventurascomclarice.
}

\section{REFERENNCIAS}

ABAR, Celina A. A. P.; BARBOSA, Lisbete Madsen. Webquest um desafio para o professor: uma solução inteligente para o uso da internet. São Paulo: Avercamp, 2008. 
BARATO. Jarbas Jovelino. A alma das webquests. Disponível em: $<$ http://webquest.xtec.cat/articles/jarbas/alma\%20daJarbas.pdf $>$. Acesso em: 21 de abril de 2014.

BOTTENTUIT JUNIOR, João Batista. Avaliação e Dinamização de um Portal Educacional de WebQuests em Língua Portuguesa. Tese de Doutoramento em Ciências da Educação, Área de Conhecimento em Tecnologia Educativa. Universidade do Minho, 2010.

BUZATO, Marcelo E. K. Letramentos Digitais e Formação de Professores. III Congresso Ibero-Americano EducaRede, 2006. Disponível em: $<$ http://www.educared.org/educa/img_conteudo/marcelobuzato.pdf $>$ Acesso em: 26 de março de 2013.

COUTINHO, C. P.; BOtTENTUIT JUNIOR, J. B. A Complexidade e os Modos De Aprender Na Sociedade Do Conhecimento, 2008. In J. Ferreira \& A. R. Simões (Org.). Actas. do XV Colóquio AFIRSE (Section Portuguaise): Complexidade: um novo paradigma para investigar e intervir em educação, s/p., Lisboa: FPCE-UL.

COUTINHO, Clara Pereira. Tecnologia Educativa e Currículo: caminhos que se cruzam ou se bifurcam? VII Colóquio Sobre Questões Curriculares, 2006. Braga: Instituto de Educação e Psicologia da Universidade do Minho.

DODGE, B. WebQuests: A Technique for Internet - Based Learning. The Distance Educator. v.1, n. 2, 1995.

DODGE, B. (2007). WebQuest. Org. Creating WebQuests. Disponível em:< http://webquest.org/index-create.php>. Acesso em: 21 de abril de 2014.

LEITE, Lígia Chiappini Moraes. Invasão da catedral: literatura e ensino em debate. 2. ed. Porto Alegre: Mercado Aberto, 1988.

LÉVY, Pierre. Cibercultura. Tradução de Carlos Irineu da Costa. São Paulo: Ed. 34, 1999.

MARCH, T. (2000). The 3 R's of WebQuests. Let's Keep Them Real, Rich, and Relevant. $\quad$ Disponível em: < http://www.infotoday.com/MMSchools/nov00/march.htm>. Acesso em: 21 de abril de 2014.

MARTÍN-BARBERO, J. Tecnicidades, identidades, alteridades: mudanças e opacidades da comunicação no novo século. In: MORAES, D. Sociedade midiatizada. Rio de Janeiro: Mauad X, 2006

O'REILLY, Tim (2005). What Is Web 2.0: Design Patterns and Business Models for the Next Generation of Software, Disponível em:< http://oreillynet.com/pub/a/oreilly/tim/news/2005/09/30/what-is-Web-20.html>. Acesso em: 12 de fevereiro de 2014.

PRENSKY, M. Digital Native, digital immmigrants. Digital Native immigrants. On the horizon, MCB University Press, Vol. 9, N.5, October, 2001. Disponível em: $<$ http://www.marcprensky.com/writing/Prensky\%20-

20Digital\%20Natives,\%20Digital\%20Immigrants\%20-\%20Part1.pdf>. Acesso em: 21 de abril de 2014 